\title{
PREVALENCE OF TSST PRODUCING COAGULASE-NEGATIVE STAPHYLOCOCCUS AUREUS IN WOUND SAMPLES AND CHARACTERIZATION OF MRSA AGAINST TEA EXTRACT
}

\author{
MOHANADOSS PONRAJ ${ }^{1 *}$, MANICHAM MALATHI ${ }^{2}$, VASUDEO ZAMBARE ${ }^{3,4}$, RAMASAMY SUBBAIYA ${ }^{1}$
}

${ }^{1}$ Department of Biological Sciences, School of Mathematics and Natural Sciences, The Copperbelt University, Riverside, Kitwe, Zambia. ${ }^{2}$ Department of Microbiology, Vivekanandha College of Arts and Science for Women, Namakkal, Tamil Nadu, India. ${ }^{3}$ Department of Research and Development, Om Biotechnologies, Nashik, Maharashtra India. ${ }^{4}$ Aesthetika Eco Research Pvt. Ltd., Nashik, Maharashtra India. Email: goldking1977@gmail.com

Received: 20 May, 2021, Revised and Accepted: 26 August 2021

\section{ABSTRACT}

Objective: Methicillin-resistant Staphylococcus aureus (MRSA) is a potential pathogen for hospital-acquired infections. This study was conducted to determine the prevalence of MRSA using tea extract.

Methods: All S. aureus isolates obtained from wound samples were studied for antibiotic resistance pattern using 23 different antibiotics. Based on coagulase negative, S. aureus isolates were identified for toxic shock syndrome toxin (TSST) gene and analyzed using PCR method. The antibacterial activities of tea extract were tested against MRSA using agar well-diffusion method

Results: A total of 100 wound samples were collected from hospital, where $75 \%$ of samples showed presence of S. aureus. About $100 \%$ resistance to cefoperazone, ampicillin, penicillin, rifampicin, novobiocin, and vancomycin antibiotics was observed. The isolates showed less resistance $<50 \%$ toward chloramphenicol (30\%), ciprofloxacin (25\%), gentamycin (52\%), amikacin (38\%), and imipenem (33\%). Twenty-five isolates were selected for MRSA characterization based on multiple drug resistance pattern. Coagulase-negative S. aureus isolates showed presence of TSST gene. Tea extract (2\%) showed effective antibacterial activity against MRSA strains.

Conclusion: The study showed the presence of MRSA at higher level and suggesting to out further epidemiological study on such infections. However cost-effective and easily available tea extract was found to be the best antimicrobial agent for preventing such bacterial infection and to reduce the risk of emerging resistance.

Keywords: Wound samples, $\beta$-lactamase, Methicillin-resistant Staphylococcus aureus, Coagulase negative, Toxic shock syndrome toxin, Tea extract.

(C) 2021 The Authors. Published by Innovare Academic Sciences Pvt Ltd. This is an open access article under the CC BY license (http://creativecommons. org/licenses/by/4.0/) DOI: http://dx.doi.org/10.22159/ijms.2021v9i5.42146. Journal homepage: https://innovareacademics.in/journals/index.php/ijms

\section{INTRODUCTION}

Staphylococcus aureus is among the leading Gram-positive bacteria causing diseases in humans and animals. S. aureus can cause wide range of illnesses ranging from minor skin infection to lifethreatening diseases such as pneumonia, meningitis, osteomyelitis, endocarditis, toxic shock syndrome (TSS), bacteremia, and sepsis [1]. MRSA is a bacterium responsible for causing several difficultto-treat infections in humans. MRSA is a strain of $S$. aureus bacteria that are resistant for larger group of antibiotics called beta-lactams. In hospitals, patients with open wounds, invasive devices, and weakened immune systems are at greater risk for infection [2] Beta-lactam antibiotics are the preferred drugs for serious $S$. aureus infections. Since the introduction of methicillin, the occurrence of MRSA strains has increased steadily, and nosocomial infections have become a serious problem worldwide. TSS is very rare but is a potentially fatal illness caused by bacterial toxin. Some strains of $S$. aureus, which produce exotoxin TSST-1, are the causative agents for TSS and other strains produce enterotoxin, which is the causative agent of $S$. aureus [3]. The increasing prevalence of multidrugresistant organisms with no treatment option available for MRSA has become a global problem.

In plant sciences, many plant extracts have shown effective antibacterial activities. However, tea extract from the leaves of plant was found to be the best source, because of its wide range of antioxidant, antiinflammatory, anticarcinogenic, and antibacterial activities against many pathogens [4]. Green tea extract is very high in polyphenols, flavonoids, catechin, and proanthocyanidins [5]. Catechins are powerful antioxidants, which are being investigated for their ability to prevent cancer and heart disease [6]. Green tea has various advantages over black tea because it undergoes minimal oxidation during the processing, which further prevents various bioactive components from being oxidized [7]. The tea extract shows wide range of activities such as antibacterial, antiviral, antioxidative, antimutagenic, and anticarcinogenic [8]. Thus, the present study provides initiative for the prevention of emerging trends toward antimicrobial resistance among wound isolates of $S$. aureus and provides a platform to initiate epidemiological studies for staphylococcal infections.

\section{METHODS}

Pus samples were collected from Namakkal government headquarters hospital and private hospitals in and around Namakkal district, Tamil Nadu, India. Pus was collected from abscesses by needle puncture and from necrotic material using standard culture method. In case of wound pus, sample was collected from patients using sterile swab. Then, it was transferred into sterile test tubes containing brain heart infusion (BHI) broth. All samples were handled aseptically and transferred to research laboratory for bacteriological investigation within $1-2 \mathrm{~h}$ of sample collection.

Loopful of culture from peptone water was streaked onto Mannitol salt agar (MSA) plate. The plates were incubated at $37^{\circ} \mathrm{C}$ for $24-48 \mathrm{~h}$. The clinical isolates were identified on the basis of colony characteristics, Gram staining morphology, and biochemical tests (indole, methyl red, Voges-Proskauer, citrate utilization, triple sugar iron agar, nitrate reduction, urease, gelatin hydrolysis, beta-galactosidase (ONPG), 
oxidation-fermentation, alkaline phosphatase, starch hydrolysis, DNase, and carbohydrate fermentation test with maltose, mannitol glucose, galactose, fructose, and sucrose).

Antibiotic sensitivity and resistance pattern were done by disc diffusion method in which the zone of growth inhibition of the test organism around theantibiotic discwas compared with the standard sensitive organism. The isolated colonies were inoculated in nutrient broth and were incubated at $37^{\circ} \mathrm{C}$ for $24 \mathrm{~h}$. After incubation, the turbidity was observed. Then, a sterile swab was dipped in the incubated culture and the excess fluid was removed by pressing the swab against test tube wall. Mueller-Hinton agar (commonly used for antibiotic susceptibility testing) plates were prepared and sterilized at $121^{\circ} \mathrm{C}$ for $15 \mathrm{~min}$ and the culture was swabbed onto the plates with sterile swab. Plates were left at room temperature to remove excess of moisture and with the help of sterile forceps, different antibiotics were placed on the agar and kept at refrigerator $30 \mathrm{~min}$ for pre-diffusion of disc. Then, the plates were incubated at $37^{\circ} \mathrm{C}$ for $24 \mathrm{~h}$. Following incubation, the zone of inhibition was noted in diameter and results were interpreted using standard chart. The standard antibiotics used were methicillin, penicillin, chloramphenicol, gentamycin, oxacillin, tobramycin, ampicillin, amikacin, trimaxazole, erythromycin, rifampicin, streptomycin, cefoperazone, levofloxacin, ciprofloxacin, tetracycline, imipenem, sparfloxacin, novobiocin, bacitracin, vancomycin, ofloxacin, clindamycin, and ceftriaxone.

Beta-lactamase production was assayed using the following method, in which the broth culture of test organism was spot inoculated onto Mueller-Hinton agar plate containing 1\% starch and penicillin, then incubated overnight at $37^{\circ} \mathrm{C}$. The plates were flooded with freshly prepared phosphate-buffered saline containing potassium iodide solution. All $S$. aureus isolates were subjected for the detection of slime production using Congo red agar plate method [9]. The BHI agar was supplemented with 5\% sucrose and Congo red. Congo red was prepared as concentrated aqueous solution, mixed with BHI media, and autoclaved at $121^{\circ} \mathrm{C}$ for $15 \mathrm{~min}$. The isolates were streaked to a length of $1.5 \mathrm{~cm}$ on the prepared plate and incubated at $37^{\circ} \mathrm{C}$ for $48 \mathrm{~h}$ and the results were recorded.

The determination of proteolytic activity in $S$. aureus was examined for the formation of zone of clearance around the colonies. Casein hydrolysis was tested on Mueller-Hinton agar (MHA) containing 10\% (W/V) skimmed milk powder by streaking $10 \mu$ l of culture suspension onto the plates and incubated at $37^{\circ} \mathrm{C}$ for $24 \mathrm{~h}$. The presence of transparent zone around the colonies showed positive for caseinase activity. The coagulase test was performed for the organism by picking the colony from nutrient agar plate with a sterile glass rod and emulsified in two drops of saline placed on the slide. A drop of undiluted human plasma was added to the emulsion and mixed gently; the prompt clumping of the organism indicates the presence of bound coagulase. The absence of clumping indicates coagulase negative.

The coagulase-negative culture, one to two loopful of cells from blood agar plates were used for DNA extraction using phenol chloroform isolation method [10]. Relative molecular mass of the PCR products was obtained by size comparison with 100 bp ladder marker (Sigma). The sequence of primers used was 5'-ATGGCAGCATCAGCTTGATA-3' and 5'-TTTCCAATAACCACCCGTTT-3' (Genei, Bangalore, India). Amplification was Aldrich, St. Louis, Missouri, United States carried out in a PCR machine using the following steps: 1 cycle at $94^{\circ} \mathrm{C}$ for $1 \mathrm{~min}$ followed by 30 cycles of denaturation for $1 \mathrm{~min}$ at $94^{\circ} \mathrm{C}$, annealing of primers for 1 min at $53^{\circ} \mathrm{C}$, and primer extension for 1 min at $72^{\circ} \mathrm{C}$ with autoextension. After 30 cycles, the PCR tubes were incubated at $72^{\circ} \mathrm{C}$ for $5 \mathrm{~min}$ before cooling to $4^{\circ} \mathrm{C}$. Visualization of amplified products was carried out by electrophoresis using agarose gel in $1 \times$ TBE buffer (TBE is $10.8 \mathrm{~g}$ of Tris, $5.5 \mathrm{~g}$ of boric acid, $0.93 \mathrm{~g}$ of EDTA, and $\mathrm{pH} 8.3$, adjusted to $1000 \mathrm{ml}$ with water) and ethidium bromide staining.

Tea extract was prepared with $2 \mathrm{~g}$ of tea powder in $100 \mathrm{ml}$ of boiling water standing for $10 \mathrm{~min}$, after cooling it was filtered and the filtrate

was used for the study. MRSA was cultured in peptone water for $18 \mathrm{~h}$ and from it $0.2 \mathrm{ml}$ of test culture was taken and added with $10 \mathrm{ml}$ of MHA and poured into sterile petri plates. After solidifying the agar media, wells were made on the agar using sterile stainless steel cork borer and were filled with $150 \mu \mathrm{l}$ of tea extract. The plates were incubated overnight at $37^{\circ} \mathrm{C}$ and the diameter of resulting zone of inhibition was measured.

\section{RESULTS}

In the current study, 100 pus samples were collected from hospital patents. The samples were from 10 to 50 age groups of $10 \mathrm{y}$ intervals (Table 1). Out of 100 processed samples, 75 samples showed positive results for the presence of $S$. aureus. Maximum infections (more than $75 \%$ ) were observed in the age group of 41-60 y followed by 21-30 y. However, only $58.82 \%$ isolates were obtained in the age group of 21 $40 \mathrm{y}$.

The isolated pus samples were further identified using biochemical and carbohydrate fermentation test (data not shown) and confirmed as $S$. aureus. Out of 75 different isolates, only 25 isolates showed multidrug resistance and all these 25 isolates showed antibiotic resistance to more than $86.9 \%$ of antibiotics (Table 2).

Based on the multiple drug resistance pattern studied, 25 isolates were processed for MRSA characterization. The test showed that 15 strains were positive, which was evident with the presence of clear colorless zone around the bacterial growth and it is also an indication of

Table 1: Distribution of study objects over age groups

\begin{tabular}{lllll}
\hline S. No. & $\begin{array}{l}\text { Age } \\
\text { groups } \\
(\mathbf{y})\end{array}$ & $\begin{array}{l}\text { Number of } \\
\text { samples } \\
\text { processed }\end{array}$ & $\begin{array}{l}\text { Number } \\
\text { of isolates } \\
\text { obtained }\end{array}$ & $\begin{array}{l}\text { \% of } \\
\text { isolates }\end{array}$ \\
\hline 1. & $10-20$ & 07 & 05 & 71.42 \\
2. & $21-30$ & 16 & 12 & 75.00 \\
3. & $31-40$ & 17 & 10 & 58.82 \\
4. & $41-50$ & 50 & 40 & 80.00 \\
5. & $51-60$ & 10 & 08 & 80.00 \\
\hline
\end{tabular}

Table 2: Multiple drug resistance pattern of MRSA

\begin{tabular}{|c|c|c|c|c|}
\hline S. No. & $\begin{array}{l}\text { Name } \\
\text { of the } \\
\text { isolates }\end{array}$ & $\begin{array}{l}\text { Number of } \\
\text { drugs showing } \\
\text { resistance }\end{array}$ & $\begin{array}{l}\text { Total } \\
\text { number of } \\
\text { antibiotics }\end{array}$ & $\begin{array}{l}\% \\
\text { resistance }\end{array}$ \\
\hline 1. & S6 & 20 & 23 & 86.90 \\
\hline 2. & S10 & 20 & 23 & 86.90 \\
\hline 3. & S11 & 21 & 23 & 91.30 \\
\hline 4. & S14 & 21 & 23 & 91.30 \\
\hline 5. & S16 & 22 & 23 & 95.60 \\
\hline 6. & S18 & 21 & 23 & 91.30 \\
\hline 7. & $\mathrm{~S} 21$ & 20 & 23 & 86.90 \\
\hline 8. & S27 & 20 & 23 & 86.90 \\
\hline 9. & S29 & 20 & 23 & 86.90 \\
\hline 10. & S33 & 20 & 23 & 86.90 \\
\hline 11. & S35 & 22 & 23 & 95.60 \\
\hline 12. & S36 & 22 & 23 & 95.60 \\
\hline 13. & S37 & 21 & 23 & 91.30 \\
\hline 14. & S38 & 21 & 23 & 91.30 \\
\hline 15. & S42 & 21 & 23 & 91.30 \\
\hline 16. & S50 & 20 & 23 & 86.90 \\
\hline 17. & S53 & 20 & 23 & 86.90 \\
\hline 18. & S55 & 21 & 23 & 91.30 \\
\hline 19. & S59 & 21 & 23 & 91.30 \\
\hline 20 & S62 & 22 & 23 & 95.60 \\
\hline 21. & S64 & 20 & 23 & 86.90 \\
\hline 22. & S67 & 21 & 23 & 91.30 \\
\hline 23 & S68 & 20 & 23 & 86.90 \\
\hline 24 & S69 & 20 & 23 & 86.90 \\
\hline 25 & S70 & 22 & 23 & 95.60 \\
\hline
\end{tabular}




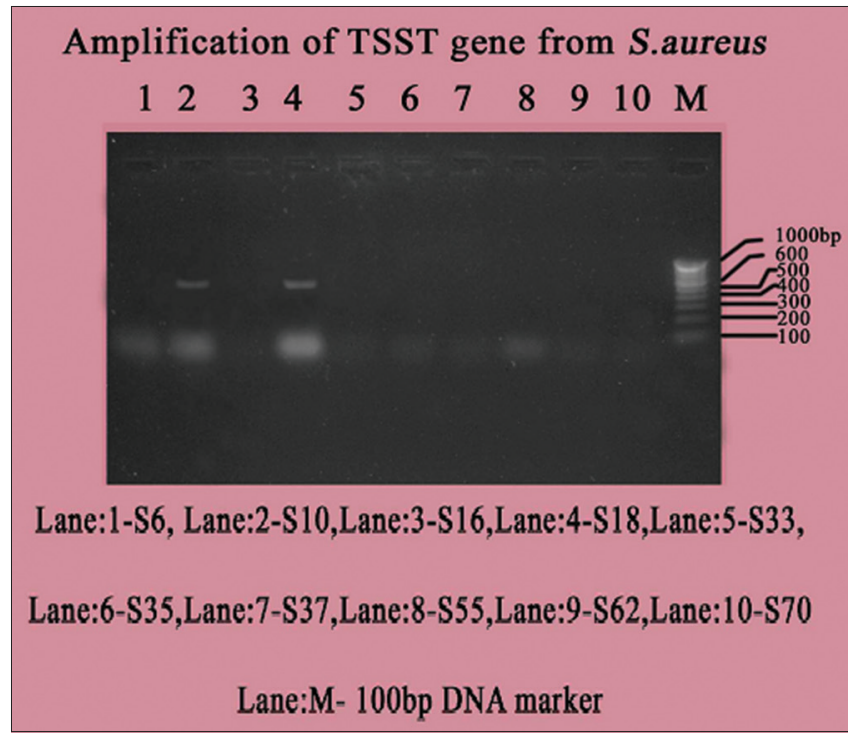

Fig. 1: Detection of TSST gene from MRSA isolates. TSST: Toxic shock syndrome toxin, MRSA: Methicillin-resistant Staphylococcus aureus

$\beta$-lactamase production and detected by the addition of iodine solution. The remaining 10 strains (MRSA strains) were further studied for TSST gene encoding and only two isolates (S10 and S18) showed TSST positive using specific primers (Fig. 1).

The antibacterial activity of tea extract against MRSA isolates was carried out using different concentration of tea extract $(1 \%, 1.5 \%$, and $2.5 \%$ ) and $2 \%$ was found to be the optimal concentration for effective antibacterial activity on MRSA (Table 3).

\section{DISCUSSION}

The morphological characterization of the culture from the collected pus samples was carried out with various selective media such as nutrient, MacConkey, and MSA medium. It was found that the prevalence of MRSA has rapidly increased from 1993 at its tertiary care center from $12 \%$ in 1992 to $80.89 \%$ in 1999 [11].

Antibiotic resistance is very common in India and the most focusing area. The prevalence of MRSA and susceptibility profile was found with the the study conducted by Indian Network of Antimicrobial Resistance group at 15 Indian territory [12]. Antibiotic resistance patterns of $S$. aureus strains isolated from clinical and food sources are also very common in Libya. Less than $50 \%$ of Libyan clinical strains were resistant to penicillin and were $\beta$-lactamase producers. However, almost $75 \%$ of Libyan strains originating from food were resistant to penicillin and were positive for $\beta$-lactamase. Fortunately, none of the Libyan $S$. aureus strains were resistant to methicillin or vancomycin [10]. The $\beta$-lactamase activities of $S$. aureus isolated from healthy individuals were quite low compared to those isolated from hospital cases. There was association of $\beta$-lactamase-producing $S$. aureus with gender and age in domiciliary condition. Similarly, in hospital isolates, no association of gender and age was observed with the occurrence of $\beta$-lactamase-positive $S$. aureus.

All MRSA isolates were subjected for the production of slime and detected using Congo red method [9], where 13 strains were found to be strongly positive, four strains as moderately positive, five strains showed to be weakly positive, and three strains showed negative results. It is reported that there are more chances of cross-infections between hospitalized patients and nursing students, than the medical students who spent less time in comparison to the nursing students who spend more time with the hospital patients and reported $90-95 \%$ of beta-lactamase producers among $S$. aureus and CoNS isolates
Table 3: Antibacterial sensitivity pattern of MRSA isolates against tea extract

\begin{tabular}{lllll}
\hline Isolates & \multicolumn{3}{l}{$\begin{array}{l}\text { Tea extract concentration and zone of } \\
\text { inhibition } \pm \text { SD }(\mathbf{m m})\end{array}$} \\
\cline { 2 - 5 } & $\mathbf{1 . 0}(\mathbf{\% )}$ & $\mathbf{1 . 5} \mathbf{( \% )}$ & $\mathbf{2 . 0}(\mathbf{\% )}$ & $\mathbf{2 . 5} \mathbf{( \% )}$ \\
\hline S6 & $4 \pm 0.5$ & $6 \pm 1.0$ & $18 \pm 1.0$ & $16 \pm 1.5$ \\
S10 & $6 \pm 1.0$ & $7 \pm 0.5$ & $20 \pm 1.2$ & $17 \pm 1.3$ \\
S16 & $3 \pm 0.3$ & $5 \pm 1.1$ & $15 \pm 1.3$ & $14 \pm 1.6$ \\
S18 & $5 \pm 1.0$ & $8 \pm 0.6$ & $21 \pm 1.0$ & $13 \pm 1.0$ \\
S33 & $6 \pm 0.4$ & $6 \pm 0.9$ & $19 \pm 1.7$ & $15 \pm 1.4$ \\
S35 & $7 \pm 1.2$ & $8 \pm 1.0$ & $19 \pm 1.0$ & $11 \pm 1.0$ \\
S37 & $2 \pm 0.5$ & $4 \pm 0.5$ & $16 \pm 1.9$ & $17 \pm 1.2$ \\
S55 & $8 \pm 1.1$ & $10 \pm 1.1$ & $18 \pm 1.0$ & $11 \pm 1.2$ \\
S62 & $3 \pm 0.8$ & $5 \pm 1.2$ & $17 \pm 1.0$ & $10 \pm 1.0$ \\
S70 & $5 \pm 0.3$ & $4 \pm 0.4$ & $19 \pm 1.1$ & $12 \pm 1.1$ \\
\hline MSRA: Methicillin-resistant Staphylococcus aureus: SD: Standard deviation
\end{tabular}

obtained from the healthy hospital staff and from the patients who were undergoing cardiac surgery [1]. The slime-producing strains also ranged from $55 \%$ to $65 \%$ of the isolates. The protease production was carried out from the positive results and 25 MRSA isolates indicated the formation of clear colorless zone around the bacterial growth. The coagulase production carried out from the positive results, showed that 25 MRSA isolates could occur only form the uncoagulated bacterial growth and was reported to be as coagulase-negative $S$. aureus. It is found that most coagulase-negative strains are resistant to $\beta$-lactam antibiotics and produce $\beta$-lactamase [13].

In comparison to the current study, TST gene encoding TSST-1 was detected in only three (7.5\%) of 40 Libyan $S$. aureus clinical strains and in none of the food strains [10]. These three strains were also positive for TSST-1 using TST-RPLA kit. In Taiwan, PCR assay using TSST-1 specific primers was employed [14]. It was found that only 3 strains (4.8\%) out of 62 strains of $S$. aureus obtained from clinical sources were found positive for carrying TST.

It was also observed that the antibacterial activity of tea extract was not demonstrated in all types of tea or in tea grown in all geographical locations for instance $20 \%$ extract of Nigeria Lipton tea showed little or no effect on Proteus sp., but the same concentration of Kenya tea produced mean inhibition zone of $6.1 \mathrm{~mm}$. The zone of inhibition produced by Kenyan tea on test organism was found to be larger, when compared with zone of inhibition produced using Nigerian Lipton tea. This may be due to the fact that it contains more active ingredients (phytochemical substances) than the Nigerian tea, which resulted in the inhibitory effect on the test organism [15].

\section{CONCLUSION}

As a conclusion, this study demonstrates that MRSA is a problem in India and especially in Namakkal district of Tamil Nadu. More number of MRSA isolates were found to be multidrug resistant, for which tea extract was found to be best and easily available source for its prevention and treatment.

\section{ACKNOWLEDGMENT}

Authors are very much thankful to the Head of the Department, Microbiology, Principal and Chairman, and Secretary, Vivekananda College who gave ideal opportunity and facilities to do complete this work.

\section{REFERENCES}

1. Shanmugam J, Gopal R, Senthil Kumar S. The prevalence, antibiogram and characterisation of Staphylococcus aureus including MRSA among the healthy staff, medical students and patients from Sri Manakula Vinayagar medical college and hospital (SMVMCH), Puducherry. 2009. Available from: http://drugstorepdfsearchcom/d/ dstepuducherrygovin $1 \mathrm{html}$. 
2. Kaplan SL. Treatment of community-associated methicillin-resistant Staphylococcus aureus infections. Pediatr Infect Dis J 2005;24:457-8.

3. Ponraj M, Rubeni V, Zambare V. Prevalence and identification of toxic shock syndrome toxin producing wound isolates of Staphylococcus aureus from Namakkal district of Tamil Nadu. Biochem Indian J 2011;5:96-103.

4. Tiwari RP, Bharti SK, Kaur HD, Dikshit RP, Hoondal GS. Synergistic antimicrobial activity of tea and antibiotics. Indian J Med Res 2005; $122: 80-4$

5. Gramza A, Pawlak LK, Korczak J, Wasowicz E, Rudzinska M. Tea extracts as free radical scavengers. Pol J Env Stud 2005;14:861-7.

6. Hamid AA, Aiyelaagbe OO, Usman LA, Ameen OM, Lawal A Antioxidants: Its medicinal and pharmacological applications. Afr J Pure Appl Chem 2010;4:142-51.

7. Chakraborty D, Chakraborti S. Bioassay-guided isolation and identification of antibacterial and antifungal component from methanolic extract of green tea leaves (Camellia sinensis). Res J Phytochem 2010;4:78-86.

8. Akiyama H, Fujji K, Yamasaki O, Oono T, Iwatsuki K. Antibacterial action of several tannins against $S$. aureus. J Antimicrob Chemother 2001;48:487-91.

9. Mathur S, Kaner CT, Atoom AM. New method for detecting slime production by coagulase negative staphylococci. J Clin Pathol 2006;42:872-4.

10. Ghenghesh KS, Ghodban AE, Marialigeti K, Esahli H, Tawil A. PCR detection of toxic shock syndrome toxin of Staphylococcus aureus from Tripoli, Libya. J Med Microbiol 2006;55:179-82.

11. Chitnis D, Verma S, Joshi S, Chitnis V, Hemwani N. Growing problem of methicillin resistant staphylococci-Indian scenario. Indian J Med Sci 2000;54:535-40.

12. Joshi S, Ray P, Manchanda V, Bajaj J, Chitnis DS, Gautam V, et al. Methicillin resistant Staphylococcus aureus (MRSA) in India: Prevalence and susceptibility pattern. Indian J Med Res 2013;137:363 69

13. Geary C, Jordens JZ, Richardson JF, Hawcpoft DM, Mitchell CJ. Epidemiological typing of coagulase negative staphylococci from nosocomial infection. J Med Microbiol 1997;4:195-203.

14. Tsen HY, Yu GK, Wang KC, Wang SJ, Chang MY, Lin LY. Comparison of the enterotoxigenic types, toxic shock syndrome toxin 1 (TSST-1) strains and antibiotic susceptibilities for enterotoxigenic Staphylococcus aureus strains isolated from food and clinical samples. Food Microbiol 1998; 15:33-41.

15. Mbata TI. Preliminary studies of the antibacterial activities of processed Kenyan and Nigerian tea. Afr J Biotechnol 2007;6:278-79. 